\title{
TEKNOLOGI DAN TIPE MASYARAKAT DALAM PERSPEKTIF GERHARD E. LENSKI, Sebuah Tinjauan Filsafat Sejarah
}

\author{
Tri Tarwiyani \\ Pendidikan Sejarah, FKIP-UNRIKA \\ Email: tritarwiyani@gmail.com
}

\section{Rangkuman}

Tulisan ini bertujuan untuk melihat pandangan Gerhard E. Lenski tentang tipe masyarakat, teknologi, serta filsafat sejarah yang terkandung dalam pemikiran Lenski tentang tipe masyarkat. Tulisan ini merupakan tulisan yang berupa studi pustaka. Tulisan ini membawa pada hasil: 1) Lenski membuat tipe masyarakat menjadi lima yaitu) masyarakat pemburu dan peramu (hunting and gathering), masyarakat hortikutural dan pastoral (horticulture and pastoralism), masyarakat agraris (agriculture), masyarakat industri (industry), dan masyarakat post industri (postindustialism); 2) Perubahan kelima tipe masyarakat ini terjadi karena teknologi dan berjalan secara evolutif dengan adanya inovasi dan perubahan atau kepunahan; 3) Filsafat sejarah yang terkandung dalam pemikiran Lenski antara laian: a) sejarah digerakan oleh teknologi yang berjalan secara evolutif dengan adanya inovasi dan kepunahan (perubahan); sejarah berjalan maju ke depan; metode yang digunakan Lenski adalah metode empiris.

Kata Kunci: Gerhard. E. Lenski, Teknologi, Tope Masyarakat, Fisafat Sejarah

\section{A. Pendahuluan}

Harian Kompas tanggal 27 April 2013 memuat sebuah artikel berjudul "Spesies Manusia Terancam Teknologi Ciptaannya”, ditulis oleh Yunanto Wiji Utomo. Artikel tersebut, dengan menggacu pada pandangan dari Nick Bostrom, seorang filsuf dari Swedia dan pada saat ini menjabat sebagai Direktur Future of Humanity Institute serta Daniel Dewey. Nick Bostrom, dalam artikel tersebut menyatakan bahwa manusia mungkin akan mampu melawan bencana alam maupun menghindari perang. Akan tetapi, manusia tidak akan mampu menghindari ancaman yang ditimbulkan oleh teknologi ciptaannya sendiri. Manusia tidak akan mampu mengontrol konsekuensi akibat teknologi ciptaanya. Hal ini karena pemahaman manusia akan teknologi serta perkembangan teknologi tidak sebanding. Pemahaman manusia akan teknologi diibaratkan masih pada level bayi terutama terkait dengan pertanggungjawaban moral maupun dalam hal penggunanan teknologi sehingga 
banyak ancaman teknologi tak terbaca. Kemiripan pandangan juga dikemukakan oleh Daniel Dewey. Daniel menyatakan bahwa komputer, sebagai "kecerdasan buatan" akan mampu menciptakan generasi komputer lebih maju lagi.

Teknologi tidak dapat dilepaskan dari kehidupan manusia. Teknologi telah ada sejak manusia mulai menggunakan peralatan (batu) untuk berburu. Teilhard de Chadine menyatakan bahwa setelah manusia terlahir ke dunia maka perjalanan evolusi tidak lagi berupa evolusi fisik tetapi lebih pada evolusi psikis, evolusi yang terkait dengan kemampuan pikir manusia. Gerhard E. Lenski bahkan menyatakan bahwa perubahan serta perkembangan masyarakat karena didorong oleh penggunaan teknologi.

Tulisan ini akan memaparkan pandangan Gerhard E. Lenski tentang teknologi dan tipe-tipe masyarakat. Oleh karena itu, persoalan yang akan dibahas dalam penelitian ini antara lain:

1. Bagaimana penggolongan masyarakat menurut Gerhard E. Lenski?

2. Bagaimana hubungan teknologi dan penggolongan masyarakat dalam pandangan Gerhard E. Lenski?

3. Bagaimana Filsafat Sejarah Gerhard E. Lenski?

Berdasarkan persoalan-persolan tersebut maka tulisan ini diberi judul "Teknologi dan Tipe Masyarakat dalam Perspektif Gerhard E. Lenski, sebuah tinjauan Filsafat Sejarah”.

\section{B. Pembahasan}

1. Masyarakat dalam perspektif Gerhard E. Lenski

Gerhard E. Lenski merupakan salah satu sosiolog dari Amerika yang cukup ternama di masa Kontemporer ini. Beberapa karyanya antara lain berjudul "Power and Previlige: A Theory of Sociologi Stratification"," Human Societies", serta "Ecological-Evolutionary Theory". 
Pandangan Lenski dibangun atas dasar teori evolusi. Lenski mengusulkan sebuah teori evolusi dan ekologi. Lenski menyatakan:

There are ultimately only three major factors determining the characteristics of the sociocultural system: 1) Human's genetic heritage; 2) The biological, physical, and social environment; and 3) The influence of prior social and cultural characteristics of the society itself.

Pandangan Lenski menjelaskan bahwa ada tiga faktor utama yang menentukan karakteristik dari sistem sosial budaya yaitu

a. Warisan genetika manusia

b. Lingkungan biologis, fisik, dan sosial

c. Pengaruh karakteristik sosial dan budaya terlebih dahulu dari masyarakat itu sendiri. Selanjutnya Lenski menyatakan:

Recall that the $9^{\text {th }}$ Postulate of Lenski's ecological-evolutionary theory was that "societies evolve in response to changes in their natural and social environments." Sociocultural change is of two types, innovation and extinction. The first involves adding new elements such as technologies, social practices, institutions, or beliefs to the system. The second type of change is, of course, the elimination of old elements in the system. While extinction certainly occurs, the process of sociocultural evolution is predominantly a cumulative process, that is, change and innovation are added far more to the system than older elements are eliminate. This, Lenski adds, is one reason why sociocultural systems have grown more complex over time.

(http://www.faculty.rsu.edu/users/f/felwell/www/Theorists/Essays/Lenski2.htm)

Kutipan tersebut menerangkan bahwa dalam postulat ke 9 teori ekologi - evolusi Lenski yang menyatakan bahwa masyarakat berkembang mengikuti perubahan lingkungan alam dan sosial. Perubahan sosial budaya terdiri dari inovasi dan kepunahan. Inovasi berarti menambahkan elemen baru seperti teknologi, praktek-praktek sosial, lembaga, atau sistem keyakinan. Sementara kepunahan terkait dengan perubahan. Ha ini dapat diartikan sebagai penghapusan elemen lama. Kepunahan yang dikaitkan dengan perubahan pasti terjadi. Proses evolusi sosiokultural didominasi proses komulatif yaitu perubahan dan inovasi. Hal 
inilah yang mendorong pertumbuhan sistem sosial budaya menjadi lebih kompleks dari waktu ke waktu.

Secara umum, ide dasar Lenski (dalam https://www.sophia.org./tutorials/lenskis-fivetypes-of-society) adalah:

“Lenski observed that a society's level of technology is crucial in determining what cultural ideas and artifacts are developed or even possible

He pointed out the importance of sociocultural evolution, the historical changes in culture that have been brought about by changes in technology"

Bertitik tolak dari pengamatannya, Lenski menemukan bahwa tingkat penggunaan teknologi di masyarakat teknologi menentukan ide-ide budaya dan artefak yang dikembangkan. Lenski menunjukkan pentingnya evolusi sosial budaya, perubahan historis dalam budaya yang telah dibawa oleh perubahan teknologi. Hal ini mengimplikasikan bahwa perubahan teknologi secara tidak langsung membawa perubahan masyarakat. Pandangan ini membawa Lenski pada beberapa tipe masyarakat yaitu (1) masyarakat pemburu dan peramu (hunting and gathering); (2) masyarakat hortikutural dan pastoral (horticulture and pastoralism); (3) masyarakat agraris (agriculture); (4) masyarakat industri (industry); (5) masyarakat post industri (postindustialism).

Selanjutnya,Lenski menggambarkan tentang kelima jenis atau tipe masyarakat tersebut. Masyarakat pemburu dan peramu (hunting and gathering) (dalam https://www.sophia.org./tutorials/lenskis-five-types-of-society) digambarkan sebagai:

"Hunting and gathering consists of using simple tools to obtain all food from wild plants and animals. From early human history until about 1800, most people lived as hunters and gatherers.Today, this technology supports few societies. Since the value of hunting versus gathering activities are roughly valued, the two sexes are regarded as having about the same social importance.

Masyarakat pemburu dan peramu merupakan bentuk masyarakat paling sederhana. Mereka menggunakan alat-alat sederhana untuk mendapatkan semua makanan dari 
tumbuhan dan satwa liar. Sejarah awal manusia sekitar 1800 tahun yang lalu, kebanyakan orang hidup sebagai pemburu dan pengumpul. Meskipun saat ini teknologi telah maju, di beberapa daerah masih dijumpai tipe masyarakat ini. Pada tipe masyarakat ini, laki-laki dan perempuan memiliki fungsi sosial yang sama. Laki-laki pada umumnya bertugas memburu hewan sementara perempuan bertugas untuk meramu. Masyarakat hortikultural dan pastoral (horticulture and pastoralism) (https://www.sophia.org./tutorials/lenskis-five-types-ofsociety) digambarkan sebagai:

Horticulture involves using tools to raise crops.

In some geographically dry regions, societies turned not raising crops, but to pastoralism, raising animals for livestock.

Pastoral people are nomadic, but horticultural people make permanent settlements.

More inequality than in hunting and gathering societies

Masyarakat hortikultural menerapkan teknologi untuk pertanian sehingga masyarakat horticultural membuat permukiman secara permanen. Hal ini berbeda dengan masyarakat Masyarakat Pastoral menerapkan teknologi pemeliharaan ternak. Masyarakat Pastoral hidup nomadik dengan menggembala ternak. Sementara masyarakat agraris (agriculture)(https://www.sophia.org./tutorials/lenskis-five-types-of-society) digambarkan sebagai:

Agriculture describes large-scale plant or animal cultivation using advanced forms of energy resources. Food surpluses and the turning of soil allow for permanent settlements

As specialization in work emerges, people use money as a form of common exchange

Agriculture expands human choices and the growth of cities, but also makes life more individualistic and impersonal

Brings huge increases in social inequality; most people live as slaves with few elite.

Masyarakat agraris digambarkan sebagai masyarakat dengan ciri kegiatan bercocok tanam atau budidaya hewan dalam skala besar serta telah menggunakan sumber energi olahan. Adanya surplus makanan dan pengolahan tanah memungkinkan untuk pemukiman permanen sehingga masyarakat agraris hidupnya menetap. Spesialisasi pekerjaan muncul. 
Anggota masyarakat telah menggunakan uang sebagai alat pertukaran pada umumnya. Masyarakat agraris telah memberikan kesempatan untuk memilih dan muncul daerahdaerah yang disebut dengan perkotaan. Hal ini berimplikasi pada hubungan masyarakatnya yang cenderung individualistis dan impersonal. Akibatnya muncul kesenjangan sosial. Sebagian besar anggota masyarakat hidup sebagai pekerja pada kelompok tertentu

Selanjutnya, Lenski menyatakan:

“...industrial societies of the present day differ greatly from agrarian. The raw materials used are far more diversified, the sources of energy quite different, and the tools far more complex and efficient.”

(https://books.google.co.id/books?id=N8M3CwAAQBAJ\&printsec=frontcover\&d $\mathrm{q}=$ gerhard $+\mathrm{e}+$ lenski\&hl=id\&sa=X\&redir_esc $=\mathrm{y} \# \mathrm{v}=$ onepage $\& \mathrm{q}=$ gerhard $\% 20 \mathrm{e} \% 2$ Olenski\&f=false (Power and Privilege: A Theory of Social Stratification by Gerhard E. Lenski).

Industry is the production and manufacturing of goods using advanced sources of energy and machines. Most people in industrial societies work in large factories under the supervision of stranger. Made the world seem smaller, raised the standard of living and lengthened life expectancy Industrialized societies increasingly attempt to reduce inequalities and extend political rights to citizens (https://www.sophia.org./tutorials/lenskis-five-types-ofsociety)..”

Masyarakat industri berbeda dengan masyarakat agraria. Perbedaan itu terlihat antara lain dari keragaman material, perbedaan sumber energi serta caranya lebih komplek dan efisien. Pada masyarakat industri, sistem produksi dan manufaktur menggunakan sumber energy dan mesin yang cukup canggih. Sebagian besar masyarakat bekerja di pabrik-pabrik besar dalam skala internasional di bawah pengawasan orang asing. Dunia menjadi terlihat lebih kecil. Masyarakat industry semakin berusaha mengurangi kesenjangan dan memperluas hak-hak politik warga negaranya.

Jenis terakhir adalah masyarakat post industri (postindustrialism) (dalam https://www.sophia.org./tutorials/lenskis-five-types-of-society) yang digambarkan: 
Postindustrialism consists of technologies organized around information and computers.

Postindustrial societies reorganize from mechanical abilities being valued in the workplace to the valuing of symbolic culture.

Masyarakat post industrialism menggunakan teknologi yang diorganisir sekitar informasi dan computer. Dengan kata lain, kegiatan produksi dalam masyarakat ini bertujuan untuk menghasilkan informasi yang memungkinkan adanya teknologi komputer. Jika masyarakat industri terpusat pada pabrik dan mesin penghasil barang material, masyarakat pasca industri terpusat pada pengelolaan dan manipulasi informasi. Oleh karena itu, produksi bergantung pada komputer dan peralatan elektronik. Itulah bebrapa tipe masyarakat menuerut Gerhard E. Lenski. Tulisan ini selanjutnya akan mencoba melihat Filsafat Sejarah yang terkandung dalam pandangan Lenski terkait dengan tipe-tipe masyarakatnya.

2. Teknologi dan penggerak sejarah

Filsafat sejarah merupakan cabang filsafat yang antara lain mempersoalkan tentang hakikat sejarah, aktor penggerak sejarah, arah dan tujuan sejarah, metode yang digunakan sejarahwan dalam membuat hukum. Berdasarkan persoalan-persoalan tersebut, secara umum Filsafat Sejarah dibedakan menjadi Filsafat Sejarah Spekulatif dan Filsafat Sejarah Kritis. Filsafat Sejarah Spekulatif antara lain mempersoalkan tentang hakikat sejarah, aktor penggerak sejarah, arah dan tujuan sejarah, hukum sejarah. Filsafat Sejarah Kritis mempersoalkan tentang metode yang digunakan para sejarawan, validitas penjelasan para sejarawan terkait dengan historiografinya.

Terkait dengan pandangan Lenski, tulisan ini akan melihat nilai atau dasar pemikiran dibalik teori Lenski tentang tipe-tipe masyarakat.

Changes in subsistence technology (food, energy, and material extraction) and population have far ranging consequences for human organization, cultural beliefs, and values ....Technology and population are, of course, closely intertwined. Technology and population combined set strong limits on widespread social organizational characteristics as well as ideas and ideologies. .... Advances in subsistence technology are important because they are often related to improvements 
in other technologies such as transportation and communications, all of which leads to greater societal growth and complexity. (http://www.faculty.rsu.edu/users/f/felwell/www/Theorists/Essays/Lenski2.htm)

Perubahan teknologi subsisten (pangan, energi, dan ekstraksi bahan) dan populasi telah membawa konsekuensi yang meluas bagi manusia, keyakinan budaya, dan nilai-nilai. Teknologi dan populasi terkait satu dengan yang lainnya. Teknologi dan populasi mempengaruhi karakteristik organisasi sosial sebagaimana ide dan ideologi. Kemajuan teknologi subsisten penting karena sering berhubungan teknologi lain seperti transportasi dan komunikasi yang pada akhirnya mengarah ke pertumbuhan sosial yang lebih besar dan kompleksitas.

Lenski's second hypothesis predicts that with technological advance, an increasing proportion of goods and services available to a society will be distributed on the basis of power.

\section{(http://www.faculty.rsu.edu/users/f/felwell/www/Theorists/Essays/Lenski2.htm)}

Hipotesis kedua Lenski memprediksi bahwa dengan kemajuan teknologi, meningkatkan proporsi barang dan layanan yang tersedia untuk masyarakat akan didistribusikan atas dasar kekuasaan. Selanjutnya dikatakan:

The technological advances responsible for this tremendous increase in productivity have also affected almost every other aspect of human existence. ... to begin with, the technological revolution of the last two centuries has destroyed economic selfsufficiency ... money plays a much more important role in the economic life of industrial societies than in agrarian. (http://www.faculty.rsu.edu/users/f/felwell/www/Theorists/Essays/Lenski2.htm).

Kemajuan teknologi bertanggung jawab dalam peningkatan produktivitas dan juga telah mempengaruhi hampir setiap aspek lain dari kehidupan manusia. Revolusi teknologi dari dua abad terakhir telah menghancurkan ekonomi swasembada, uang memainkan peran yang jauh lebih penting dalam kehidupan ekonomi masyarakat industri daripada di agraria.

Begitu penting teknologi dalam pandangan Lenski. Lenski, dengan melihat teknologi yang digunakan oleh masyarakat membawa Lenski pada konsep tipe-tipe masyarakat. Agaknya dari keterangan di atas, dapat ditarik benang merah. Pandangan 
Lenski yang menempatkan teknologi sebagai pusat perhatiannya maka dapat dikatakan bahwa bagi Lenski yang menggerakkan sejarah manusia adalah teknologi. Teknologi yang semakin kompleks telah membawa kompleksitas manusia. Teknologi bahkan telah merubah tata susunan sosial masyarakat, baik dari segi pelapisan masyarakat maupun interaksi antar anggotanya. Oleh karena itu, terkait dengan persoalan aktor penggerak sejarah maka dalam persepktif Lenski, sejarah digerakkan oleh teknologi.

Selain itu, sejarah jika di lihat dari pandangan tipe masyarakat Lenski maka dapat dikatakan bahwa sejarah selalu berubah secara bertahap dan bergerak maju ke depan. Hal ini berdasarkan landasan pemikirannya yang didasarkan pada teori evolusi. Meskipun demikian, perubahan masyarakat menuju tipe berikutnya bukan perubahan yang ekstrim, dalam arti masyarakat lama menghilang dan diantikan masyarakat tipe baru. Sebuah masyarakat industri terkadang masih menyisakan tipe masyarakat agraris atau bahkan masyarakat meramu dan berburu. Hal ini karena peubahan dalam masyarakat terjadi karena adanya faktor inovasi dan kepunahan atau perubahan.

Sementara, dalam penyelidikannya, Lenski sepertinya menggunakan metode empiris, sebuah metode yang biasa digunakan kaum saintis. Metode empiris merupakan metode yang menggunakan pengamatan maupun pengalaman. Pengamatan atau pengalaman inilah yang akan membawa pada kebenaran pengetahuan. Demikian beberapa benang merah yang dapat ditarik dari penjelasan Lenski tentang tipe masyarakat.

\section{Kesimpulan}

Berdasarakan penjelasan di atas maka dapat ditarik kesimpulan:

1. Lenski menggolongkan tipe masyarakat yaitu: masyarakat pemburu dan peramu (hunting and gathering); masyarakat hortikutural dan pastoral (horticulture and pastoralism); masyarakat agraris (agriculture); masyarakat industri (industry); masyarakat post industri (postindustialism).

2. Perubahan kelima masyarakat ini terjadi karena adanya teknologi dan penggunaan teknologi dalam masyarakat. Semakin kompleks masyarakat maka teknologi yang digunakan semakin komples. Antara teknologi dan masyarakat berkaitan satu dengan yanglainnya. 
3. Terkait dengan Filsafat Sejarah maka dapat ditarik benang merah:

a. Penggerak sejarah dalam persepektif Lenski adalah teknologi.

b. Sejarah itu sendiri akan bergerak terus ke depan dengan jalan evolusi yang dipengaruhi oleh inovasi dan perubahan atau kepunahan.

c. Metode yang digunakan oleh Lenski adalah metode empiris. Lenski menggunakan pengamatan maupun pengalamannya dalam membuat teorinya ini.

\section{Daftar Bacaan}

Ankersmit, F. R., 1987, Refleksi Tentang Sejarah, pendapat-pendapat modern tentang Filsafat Sejarah (terj. Dick Hartoko), Gramedia, Jakarta.

Meyerhoff, Hans, 1959, The Philosophy of History in Our Time, an anthology selected and with an introduction and commentary by hans Meyerhoff, Doubleday \& Company. Inc., New York

http://www.faculty.rsu.edu/users/f/felwell/www/Theorists/Essays/Lenski2.htm, diunduh: 1Januari 2016.

https://books.google.co.id/books?id=N8M3CwAAQBAJ\&printsec=frontcover\&dq=gerhar

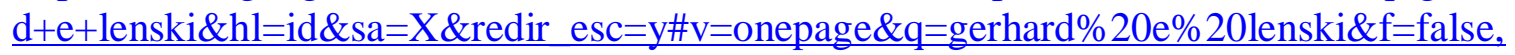
Power and Privilege: A Theory of Social Stratification by Gerhard E. Lenski, (diunduh: 20 Januari 2016

https://www.sophia.org./tutorials/lenskis-five-types-of-society, diunduh 22 Januari 2016 